\title{
HUBUNGAN ANTARA FLEKSIBILITAS DAN KEKUATAN OTOT LENGAN DENGAN KECEPATAN RENANG
}

\author{
The Correlation between Flexibility and Strength of Arm Muscle with \\ Swimming Speed
}

\author{
Djohan Aras, Abdullah Arsyad, Nurhikmawaty Hasbiah \\ Program Studi Fisioterapi, Fakultas Kedokteran, Universitas Hasanuddin, Makassar \\ (djohanaras.da@gmail.com)
}

\begin{abstract}
ABSTRAK
Kecepatan adalah aset utama atlet renang. Penelitian terbaru menunjukkan variabel fleksibilitas dan kekuatan otot lengan sangat memengaruhi kecepatan renang individu. Penelitian ini bertujuan mengetahui hubungan antara fleksibilitas dan kekuatan otot lengan pada atlet renang gaya bebas di Makassar. Desain penelitian ini adalah cross sectional dengan jumlah sampel 20 orang atlet yang berusia 12-18 tahun. Variabel independen yang diukur adalah fleksibilitas dan kekuatan otot lengan. Variabel dependen yang diukur adalah kecepatan renang melalui tes renang gaya bebas 25 meter. Analisis bivariat digunakan untuk menganalisis hubungan fleksibilitas dan kekuatan otot lengan dengan kecepatan pada atlet renang. Hasil penelitian menunjukkan adanya korelasi positif antara fleksibilitas dengan kecepatan $(\mathrm{p}=0.001$; $\mathrm{R} 2=0.512)$ dan kekuatan otot lengan dengan kecepatan $(\mathrm{p}=0.001$; R2=0.746). Disimpulkan bahwa semakin tinggi nilai fleksibilitas, semakin tinggi kecepatan renang. Semakin besar nilai kekuatan otot lengan, semakin tinggi kecepatan renang.
\end{abstract}

Kata kunci : Fleksibilitas, kekuatan otot lengan, kecepatan renang

ABSTRACT

Velocity is the main asset of swimmer. The newest study shows that flexibilty and the strength of arm muscle influence the velocity of the swimmer. This study is aimed to identify the coreelation between the flexibility and the strength of arm muscle with the velocity of freestyle swimmer at Makassar. The study design was cross-sectional with a sample of 20 athletes aged 12-18 years olh. The independent variable that was measured were flexibility and the strenght of arm muscle. Dependent variable was velocity of swimming through freestyle swimming 25 metres test. The bivariate analysis is used to analyze the relationship between flexibility and the strength of arm muscle with the velocity of swimming. The results showed a positive correlation between flexibility with velocity ( $p$ $=0.001 ; R 2=0512)$ and arm muscle strength with velocity $(p=0.001 ; R 2=0.746)$. It was concluded that the higher the value of flexibility, the higher the velocity of swimming. The higher of flexibility, higher the velocity of swimming. The higher of the strength of arm muscle score, higher the velocity of swimming.

Keywords : Flexibility, arm muscle strength, velocity of swimming 


\section{PENDAHULUAN}

Olahraga prestasi khususnya renang pada saat ini telah berkembang menjadi suatu kegiatan yang terlembaga dengan struktur organisasi formal. Perkembangan ini mendorong para pembina dan pelatih olahraga bekerja lebih efektif dalam mencari serta membina calon-calon atlet yang berbakat. Hal ini dilakukan di semua negara termasuk di Indonesia yang berusaha keras melakukan pembinaan atlet demi memperoleh prestasi yang membanggakan.

Prestasi olahraga renang di daerah dan nasional banyak ditandai dengan masa-masa kesuksesan yang diraih oleh para atlet terutama di tingkat Asia Tenggara. Berdasarkan fakta di lapangan, saat ini atlet renang Indonesia masih sangat sulit bersaing dengan atlet dunia yang senatiasa melakukan lonjakan prestasi. Perenang Indonesia memang mampu meningkatkan prestasi, tetapi sulit mengejar laju peningkatan prestasi negara lain. Pada 5 kali SEA Games terakhir, tim renang Indonesia menyumbang 6 medali emas dari 32 medali yang diperebutkan di Palembang, tahun 2009 di Laos 2 emas, Thailand 2007 hanya 2 perak, Filipina 2005 sebanyak 4 emas dan di Vietman 2003 hanya 1 medali emas. ${ }^{1}$

Dalam rangka meningkatkan prestasi olahraga, khususnya dalam cabang olahraga renang diperlukan latihan yang dapat meningkatkan kondisi fisik yang prima. ${ }^{2}$ Komponen fisik yang dibutuhkan dan perlu dikembangkan pada cabang olahraga renang adalah kekuatan otot, daya tahan otot, agilitas, fleksibilitas, dan kekuatan. Dari beberapa komponen kondisi fisik tersebut ada tiga kelompok unsur utama dari kondisi fisik yang dibutuhkan untuk dapat melakukan unjuk kerja dalam olahraga renang, yaitu: fleksibilitas, kecepatan, dan kekuatan. ${ }^{3}$

Fleksibilitas adalah kemampuan tubuh mengulur diri seluas-luasnya yang ditunjang oleh luasnya gerakan pada sendi. Kemampuan untuk menggerakkan tubuh dan anggota tubuh seluasluasnya, berhubungan erat dengan kemampuan gerakan kelompok otot besar dan kapasitas kinerjanya. Kemampuan ini terkait pula dengan kemampuan peregangan otot dan jaringan sekeliling sendi. ${ }^{4}$

Kekuatan merupakan unsur penting dalam tubuh manusia. ${ }^{5}$ Kekuatan adalah komponen yang sangat penting guna meningkatkan kondisi fisik seseorang secara keseluruhan. Menurut Nurhasan, kekuatan adalah kemampuan sekelompok otot dalam menahan beban secara maksimal. ${ }^{6} \mathrm{Se}-$ cara sederhana kekuatan dapat diartikan sebagai kemampuan untuk memberikan tenaga terhadap tekanan. Pendapat lain juga dikemukakan oleh Sukadiyanto, kekuatan adalah kemampuan otot atau sekelompok otot untuk mengatasi beban atau tahanan. ${ }^{?}$

Fleksibilitas dan kekuatan tersebut berpengaruh pada kecepatan atlet. Kecepatan adalah kemampuan untuk melakukan gerakan dalam waktu yang singkat. ${ }^{8}$ Ada beberapa faktor yang mempengaruhi kecepatan, seperti yang dikemukakan oleh Wilmore bahwa kecepatan tergantung dari beberapa faktor yang mempengaruhinya, yaitu strength, waktu reaksi (reaction time), dan fleksibilitas. ${ }^{9}$ Berdasarkan studi pendahuluan yang dilakukan peneliti, ditemukan bahwa ada perbedaan kecepatan renang dari tiap-tiap atlet pada beberapa klub renang di Kota Makassar. Oleh karena itu, penulis tertarik untuk melakukan penelitian mengenai hubungan antara fleksibilitas dan kekuatan otot lengan terhadap kecepatan atlet renang di Kota Makassar tahun 2016.

\section{BAHAN DAN METODE}

Penelitian ini dilaksanakan di kolam renang Mattoanging dan kolam renang UNM Makassar. Jenis penelitian yang digunakan adalah penelitian korelasional dengan jenis rancangan cross sectional. Populasi penelitian adalah seluruh anggota Klub Renang Garuda laut dan Atlet Renang Mattoangin Makassar tahun 2016 sebanyak 68 orang dengan usia 12-18 tahun. Sampel penelitian dipilih dari jumlah populasi penelitian dengan ketentuan memenuhi kriteria inklusi, yaitu berjenis kelamin laki-laki, aktif mengikuti latihan minimal dua kali sepekan, lama latihan minimal satu tahun, usia 12-18 tahun, bersedia menjadi responden dan komunikatif serta hadir untuk mengikuti pengukuran fleksibilitas, kekuatan otot lengan, dan kecepatan renang.

Pengumpulan data dilakukan oleh peneliti dengan melakukan pengukuran fleksibilitas atlet dengan cara sit and reach test. Pengukuran yang dinilai yaitu jarak kepala sampai lutut menggunakan alat flexsometer dengan satuan sentimeter. 
Tabel 1. Karakteristik Responden Penelitian

\begin{tabular}{ccc}
\hline Karakteristik & $\mathbf{n}$ & $\mathbf{\%}$ \\
\hline Jenis Kelamin & 21 & 100.0 \\
$\quad$ Laki-laki & 1 & 4.8 \\
Umur (tahun) & & \\
12 & 4 & 19.0 \\
13 & 3 & 14.3 \\
14 & 5 & 23.8 \\
15 & 4 & 19.0 \\
16 & 4 & 19.0 \\
18 & & \\
Pendidikan & & \\
Perguruan Tinggi & 4 & 19.0 \\
SMA & 8 & 38.1 \\
SMP & 9 & 42.9 \\
\hline
\end{tabular}

Sumber: Data Primer, 2016

Selanjutnya dilakukan pengukuran kekuatan otot lengan dengan alat push and pull dynamometer. Tes dilakukan dengan mengukur kekuatan tarikan setiap sampel. Pengukuran dilanjutkan dengan pengukuran kecepatan renang gaya bebas 25 meter. Pengukuran dilakukan dengan cara menilai waktu renang yang dicapai untuk menempuh jarak 25 meter. Pengukuran dinilai menggunakan stopwatch dengan satuan detik. Data yang diperoleh merupakan data primer, yaitu nilai fleksibilitas, kekuatan otot lengan dan kecepatan renang. Data yang diperoleh dianalisis dengan teknik analisis bivariat pengujian pearson menggunakan sistem komputerisasi dan disajikan dalam bentuk tabel dan narasi.

\section{HASIL}

Tabel 1 menunjukkan jumlah responden sebanyak 21 orang. Berdasarkan usia, responden terbanyak berada di usia 15 tahun (5 orang) dan paling sedikit di usia 12 tahun (1 orang). Dari segi pendidikan, jumlah responden terbanyak berpendidikan SMP yaitu sebanyak 9 orang, dan yang paling sedikit responden berpendidikan di Pergu- ruan Tinggi sebanyak 4 orang responden. Hasil pengukuran fleksibilitas yang dilakukan pada 21 orang sampel, didapatkan rerata fleksibilitas subyek adalah 14,69 cm (SD=5.5). Pada Gambar 1 menunjukkan klasifikasi nilai fleksibilitas dari 21 orang sampel, didapatkan yang tertinggi berada pada kategori fleksibilitas sangat baik yakni sebanyak 6 orang $(28.6 \%)$, sedangkan kategori yang paling sedikit terdapat pada kategori fleksibilitas kurang, yakni sebanyak 2 orang (9.5\%). Hasil pengukuran kekuatan otot lengan yang dilakukan pada 21 orang sampel, didapatkan rerata kekuatan otot lengan adalah $20.28 \mathrm{~kg}(\mathrm{SD}=5.69)$. Gambar 2 menunjukkan klasifikasi nilai kekuatan otot lengan dari 21 orang sampel. Didapatkan kategori tertinggi berada pada kategori kekuatan otot sedang yakni sebanyak 12 orang (57.1\%), sedangkan kategori yang paling sedikit terdapat pada kategori kekuatan otot kurang sekali, yakni sebanyak 4 orang (19\%). Hasil pengukuran kecepatan renang yang dilakukan pada 21 orang sampel, didapatkan rerata kecepatan renang pada sampel adalah 13.91 detik (SD 1.32). Gambar 3 menunjukkan klasifikasi kecepatan renang dari 21 orang sampel. Didapatkan kategori tertinggi berada pada kategori cepat yakni sebanyak 10 orang (47.6\%), sedangkan kategori yang paling sedikit terdapat pada kategori sangat cepat, yakni sebanyak 5 orang (23.8\%).

Tabel 2 menunjukkan bahwa hasil uji korelasi variabel independen dan dependen berdasarkan uji korelasi dengan menggunakan pearson correlation, diperoleh nilai signifikan. Tabel 2 juga menunjukkan bahwa diperoleh nilai signifikan antara fleksibilitas dengan tingkat kecepatan renang pada subyek penelitian sebesar $\mathrm{p}=0,001$ yang lebih kecil dari $0,05(p<\alpha)$. Hal ini menunjukkan bahwa ada hubungan bermakna antara fleksibilitas dengan kecepatan renang. Nilai korelasi Pearson $(r=-0,716)$ menunjukkan arah korelasi negatif dengan kekuatan korelasi yang kuat. Nilai $\mathrm{r}^{2}$ sebesar 0,512 atau $51,2 \%$ menunjukkan besar kontribusi

Tabel 2. Hubungan antara Fleksibilitas dan Kekuatan Otot Lengan dengan Kecepatan Renang

\begin{tabular}{lccc}
\hline \multirow{2}{*}{ Variabel } & \multicolumn{3}{c}{ Kecepatan Renang } \\
\cline { 2 - 4 } & $\mathbf{r}$ & $\mathbf{p}$ & $\mathbf{r}^{\mathbf{2}}$ \\
\hline Fleksibilitas & -0.716 & 0.001 & 0.512 \\
Kekuatan Otot Lengan & -0.864 & 0.001 & 0.746 \\
\hline
\end{tabular}

Sumber: Data Primer, 2016 


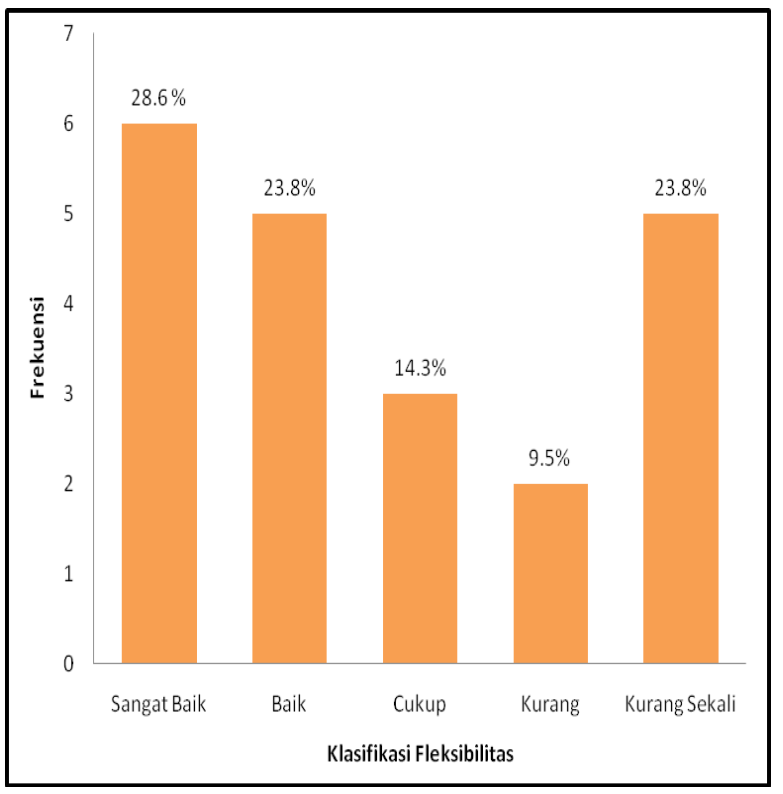

Gambar 1. Klasifikasi Nilai Fleksibilitas

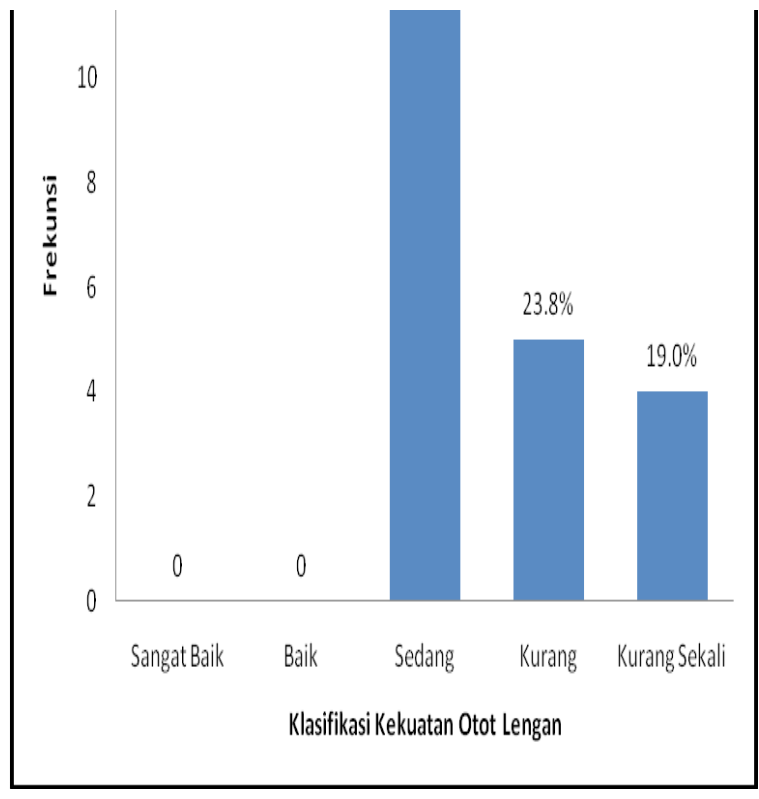

Gambar 2. Klasifikasi Nilai Kekuatan Otot Lengan

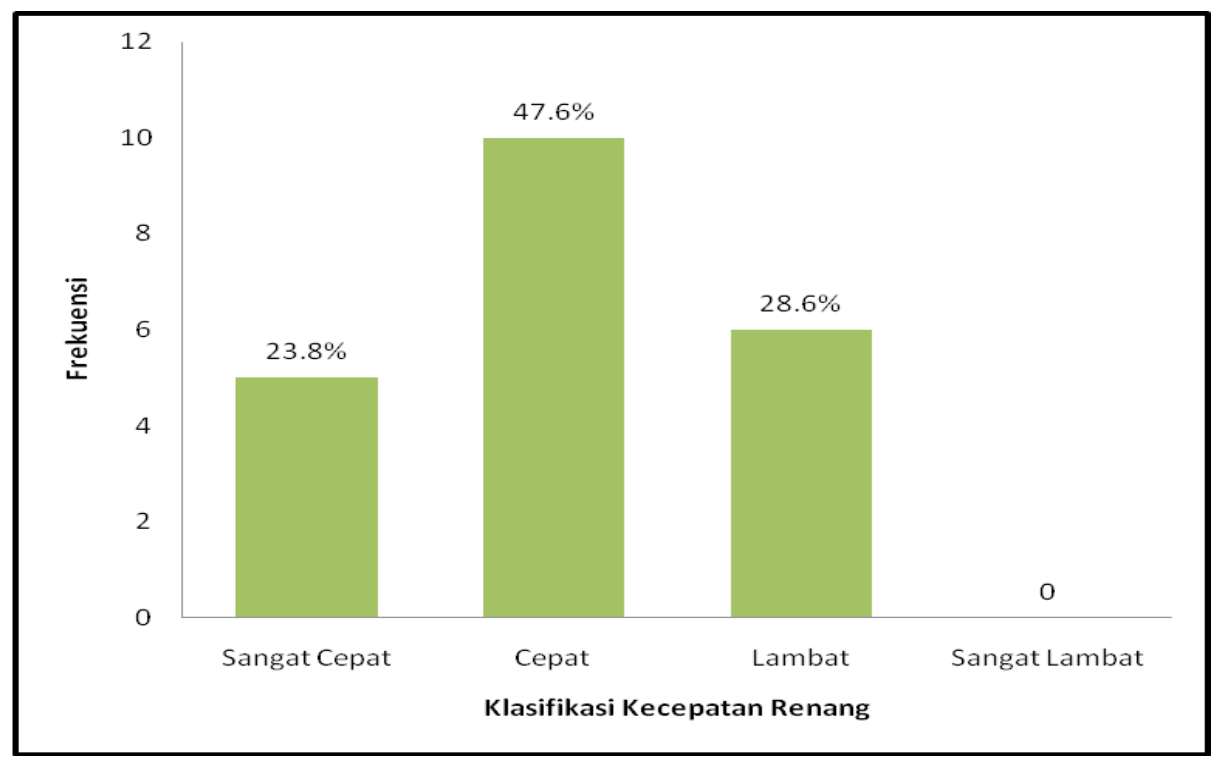

Gambar 3. Distribusi Kecepatan Renang

hubungan kekuatan otot lengan dengan kecepatan renang. Nilai signifikan antara kekuatan otot lengan dengan tingkat kecepatan renang pada subyek penelitian sebesar $\mathrm{p}=0,001$ yang lebih kecil dari $0,05(p<\alpha)$. Hal ini menunjukkan bahwa ada hubungan bermakna antara kekuatan otot lengan dengan kecepatan renang. Nilai korelasi pearson $(\mathrm{r}=-0,864)$ menunjukkan korelasi negatif dengan kekuatan korelasi sangat kuat. Nilai $\mathrm{r}^{2}$ sebesar
0,746 atau 74,6\% menunjukkan besar kontribusi hubungan kekuatan otot lengan dengan kecepatan renang.

\section{PEMBAHASAN}

Hasil penelitian yang telah dilakukan diperoleh hubungan bermakna antara fleksibilitas dengan kecepatan renang dengan nilai $p=0,001(p<0,05)$. Hasil ini sejalan dengan pene- 
litian yang dilakukan oleh Jorgic, et al., di Serbia pada 70 mahasiswa yang aktif mengikuti kegiatan renang minimal dua kali dalam seminggu. ${ }^{10}$ Pada penelitian lain yang juga dilakukan Jorgic, et al., pada 30 anak yang aktif berenang selama 2 tahun menunjukkan hubungan yang kuat antara fleksibilitas dengan kecepatan renang. ${ }^{11}$ Penelitian lain yang dilakukan oleh Yudha juga menunjukkan hasil yang sama bahwa ada hubungan yang signifikan antara fleksibilitas dan daya tahan jantung paru terhadap kecepatan renang gaya bebas 25 meter. $^{12}$

Fleksibilitas yang baik membantu dalam elastisitas otot dan memberikan jangkauan yang lebih luas gerak pada sendi. Hal ini memberikan kemudahan dalam gerakan tubuh. ${ }^{13}$ Kemampuan untuk menggerakkan tubuh dan anggota tubuh seluas-luasnya, berhubungan erat dengan kemampuan gerakan kelompok otot besar dan kapasitas kinerjanya. Kemampuan ini terkait pula dengan kemampuan peregangan otot dan jaringan sekeliling sendi. ${ }^{4}$ Kemampuan yang cepat dan lincah dalam mengubah arah memerlukan fleksibilitas tubuh atau bagian tubuh yang terlibat dalam kegiatan tersebut. Melakukan perubahan kecepatan dan arah gerakan dapat mengkibatkan regangan otot yang terlalu kuat sehingga memungkinkan terjadinya cedera otot (muscle strain) apabila fleksibilitas otot yang dimiliki rendah.

Fleksibilitas juga sangat diperlukan oleh atlet karena atlet dengan fleksibilitas yang baik tidak akan mudah mengalami cedera, selain itu juga mempunyai peluang yang lebih besar untuk menciptakan prestasi yang maksimal dibandingkan dengan atlet yang kurang fleksibilitasnya. Hal ini diperjelas oleh Bahagia dalam penelitiannya yang menyebutkan bahwa kemampuan fleksibilitas yang terbatas dapat menyebabkan penguasaan teknik yang kurang baik dan prestasi rendah. Menurut Kasiyo, pengalaman menunjukkan bahwa elastisitas otot berkurang sesudah masa tidak aktif yang panjang. Sebaliknya, peregangan otot yang teratur rupanya dapat meningkatkan elastisitas otot. Tujuan latihan fleksibilitas adalah untuk memaksimalkan elastisitas otot. Oleh karena itu, agar elastisitas otot dapat diperoleh dengan hasil yang maksimal, maka latihan untuk meningkatkan fleksibilitas sangat diperlukan, sebab fleksibilitas seseorang dapat menurun apabila tidak dilatih. ${ }^{14}$
Pada penelitian yang dilakukan, diperoleh hubungan antara kekuatan otot lengan dengan kecepatan renang, artinya semakin tinggi nilai kekuatan otot lengan semakin cepat waktu yang diperlukan untuk menempuh jarak renang 25 meter. Hubungan ini memiliki nilai korelasi cukup kuat ( $\mathrm{r}=-0,864 ; \mathrm{p}=0,001)$. Penelitian Zenic et al., di Kroasia menunjukkan adanya pengaruh nilai kekuatan otot lengan dan fleksibilitas dengan hasil kecepatan renang pada atlet. ${ }^{15}$ Hasil ini sejalan dengan penelitian yang dilakukan Mulyana pada 20 orang atlet usia 14 tahun yang menunjukkan adanya hubungan yang signifikan antara kekuatan otot lengan dengan kemampuan renang gaya bebas 50 Meter di Sasana Mandala Ganesa Bandung. ${ }^{16}$

Untuk melakukan renang gaya bebas yang cepat dibutuhkan kekuatan otot lengan. Kekuatan otot lengan digunakan untuk melakukan gerakan yang bersifat eksplosif. Kemampuan untuk menggerakkan lengan ini dipengaruhi oleh kontraksi otot-otot yang bekerja untuk menggerakkan lengan. Otot-otot lengan utama sebagai penggerak dalam renang gaya bebas adalah $m$. deltoideus, $m$. triceps brachii,m. latisimus dorsi, $m$. teres minor, m. infraspinatus, m. brachialis, m.biceps brachii, $m$. brachioradialis, $m$. flexor carpi radialis dan m.flexor carpi ulnaris. Kontraksi otot ini menghasilkan tenaga eksternal untuk menggerakkan anggota tubuh. Kekuatan lengan berhubungan erat dengan kemampuan renang pada gaya bebas dengan menggunakan kekuatan dinamis karena dalam melakukan gaya tersebut perenang berusaha untuk memindahkan posisi badan dari ujung kolam ke ujung kolam. Dalam hal ini, lengan adalah alat penggerak dalam melakukan ayunan menghambat tahanan di dalam air guna membawa tubuh didalam menyikapi teknik-teknik yang ada pada gaya bebas itu sendiri. ${ }^{15}$

Renang yang dilakukan secara berulang secara teratur bermanfaat dalam meningkatkan suplai darah kaya oksigen ke otot-otot rangka. Oksigen tersebut penting untuk respirasi seluler secara aerob. Olahraga aerobik seperti renang membantu dalam membangun daya tahan otot untuk melakukan aktivitas berkepanjangan. Olahraga aerobik menyebabkan perubahan secara bertahap beberapa serat glikolitik cepat menjadi serat oksidatif-glikolitik cepat. Sistem kardiovaskular dan respirasi juga dapat mengalami peningkatan 
kualitas sehingga suplai oksigen dan nutrisi ke otot juga semakin baik.

\section{KESIMPULAN DAN SARAN}

Peneliti menyimpulkan bahwa ada hubungan bermakna antara fleksibilitas dan kekuatan otot lengan dengan kecepatan renang gaya bebas 25 meter pada atlet renang di Kota Makassar tahun 2016. Semakin tinggi nilai fleksibilitas dan kekuatan otot lengan individu, maka semakin cepat waktu yang dibutuhkan untuk menempuh jarak 25 meter, dalam hal ini semakin tinggi kecepatan renang individu. Bagi atlet renang hendaknya menambah latihan-latihan fisik lain yang mendukung seperti latihan untuk meningkatkan fleksibilitas dan kekuatan otot lengan guna meningkatkan prestasi.

\section{DAFTAR PUSTAKA}

1. Setiawan, TT., Erman, S., \& Fajar, VH. Pengembangan Jump Power Meter Sebagai Alat Pengukur Power Tungkai. Jurnal IPTEK Olahraga. 2013.15.

2. Sajoto. M. Pembinaan Kondisis Fisik dalam Olahraga. Jakarta: Depdikbud; 1995.

3. Kosasih, Engkos. Teknik dan Program Latihan. Jakarta: Balai Pustaka; 1993.

4. Ikhsan, Nur Halim. Tes dan Pengukuran Kesegaran Jasmani. Makassar: Badan Penerbit Universitas Negeri Makassar; 2011.

5. Lutan, Rusli dan Adang Suherman. Pengukuran dan Evaluasi. Penjaskes. Jakarta: Depdikbud; 2000.

6. Nurhasan. Aktivitas Kebugaran. Jakarta: Depdiknas; 2005.

7. Sukadiyanto. Pengantar Teori dan Metodologi Melatih Fisik. Yogyakarta: FIK Universitas Negeri Yogyakarta; 2005.
8. ACSM. ACSM's Guidelines for Exercise Testing and Prescription. $8^{\text {th }}$ Edition. Canada: ACSM Publications; 2009.

9. Harsono. Latihan Kondisi Fisik, Jakarta: KONI Pusat; 1993.

10. Jorgic, bogan., Aleksandrovic. Marko., Tomislav, Okicic., and Madic, Dejan. The Influence of Flexibility Onto the Swimming Results in Student of Sport and Physical Education. Sport Science 2. 2009; 1 : 91-94.

11. Jorgic, bogan., Tomislav, Okicic., Aleksandrovic. Marko., and Madic, Dejan. Influence of Basic And Spesific Motor Abilities on Swimming Results. Acta Kinesiologica 4. 2010. $2: 73-77$.

12. Yudha, Enggar Cahyandaru. Hubungan Antara Kecepatan, Kelentukan, dan Daya Tahan Vo2Max terhadap Prestasi Renang Gaya Bebas 50 Meter di Pusat Pembinaan Atlet Berbakat (PAB) Daerah Istimewa Yogyakarta. Yogyakarta: Fakultas Ilmu Keolahragaan Universitas Negeri Yogyakarta; 2015.

13. Nelson G., Arnold and Kokkonen, Jouko. Stretching Anatomy. Human Kinatics: United States; 2007.

14. Kasiyo, Dwijowinoto. Renang Perkembangan Pengajaran Teknik dan Taktik. Semarang: IKIP Semarang; 1993.

15. Zenic, N., Antulov, J., \& Cavar, M. Biological Age As A Fundamental Anthropological Assumption Of Training In The Sports Swimming In Croatian. Summer School of Kinesiology Republic Of Croatia; 2007. Pp. 270-273.

16. Mulyana, Boyke. Hubungan Antara Power Lengan dengan Kemampuan Renang Gaya Bebas 50 Meter Sasana Mandala Ganesa. Bandung; 2010. 